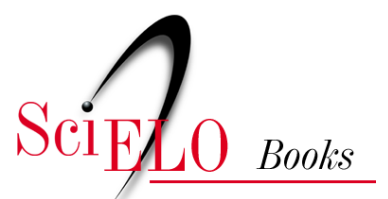

\title{
Capítulo 4. A Revolução Demográfica dos Povos Indígenas a experiência dos Kaiabi do Parque Indígena do Xingu, Mato Grosso
}

\author{
Heloísa Pagliaro
}

\section{SciELO Books / SciELO Livros / SciELO Libros}

PAGLIARO, H. A Revolução Demográfica dos Povos Indígenas: a experiência dos Kaiabi do Parque Indígena do Xingu, Mato Grosso. In: PAGLIARO, H., AZEVEDO, MM., and SANTOS, RV., comps.

Demografia dos povos indígenas no Brasil [online]. Rio de Janeiro: Editora FIOCRUZ, 2005, pp. 79102. Saúde dos Povos Índigenas collection. ISBN: 978-85-7541-254-1. https://doi.org/10.7476/9788575412541.0005.

\section{(1) (1) (2)}

All the contents of this work, except where otherwise noted, is licensed under a Creative Commons Attribution-Non Commercial-ShareAlike 3.0 Unported.

Todo o conteúdo deste trabalho, exceto quando houver ressalva, é publicado sob a licença Creative Commons Atribuição - Uso Não Comercial - Partilha nos Mesmos Termos 3.0 Não adaptada. 


\section{A Revolução Demográfica dos Povos Indígenas: a experiência dos Kaiabi do Parque Indígena do Xingu, Mato Grosso}

\section{Introdução}

Evidências de que as populações indígenas no Brasil voltaram a crescer nas últimas décadas do século XX vêm sendo apresentadas em trabalhos recentes, contrariando as previsões de declínio apontadas por Ribeiro (1957 e 1991).

Entre a chegada dos europeus ao Brasil e o início do século XX a população indígena decresceu continuamente, reduzindo-se a cerca de 230 grupos tribais e 100 mil indivíduos (Melatti, 1993). Estima-se que durante esse período, aproximadamente $85 \%$ das línguas indígenas tenham desaparecido (ISA, 2001). Para a década de 1950, Ribeiro (1957) estimou em 143 o número de grupos tribais: 87 a menos em meio século. No final do século XX, havia 216 nações identificadas, com uma população de 350 mil indivíduos, vivendo em 561 áreas reconhecidas, mas, em sua grande maioria, não demarcadas (ISA, 2001). No recenseamento da população brasileira, realizado em 2000 pelo Instituto Brasileiro de Geografia e Estatística (IBGE), 734 mil pessoas identificaram-se como índios (Pereira, neste volume).

Alguns povos indígenas têm crescido, em média, de 3 a $5 \%$ ao ano, nos últimos decênios, entre estes, destacam-se: Nambiquara (Price, 1994); Krahô (Melatti, 1999); Bakairi (Picchi, 1994); Canela (Greene G Crocker, 1994); Xavánte de Pimentel Barbosa (Flowers, 1994, Coimbra Jr. et al., 2004); Xavánte de Sangradouro-Volta Grande (Souza G Santos, 2001); Tenetehara (Gomes, 2002); Panará (Baruzzi et al., 1994); Juruna (Pagliaro et al., 2003); Kamaiurá (Pagliaro et al., 2004); Txikão (Maia et al., 2004), assim como o conjunto dos povos do Parque Indígena do Xingu (Rodrigues, 1999).

Entre os fatores arrolados para explicar o crescimento demográfico observado destacam-se: o aumento da capacidade de resistência dessas populações às agressões de agentes infecciosos, com a menor ocorrência de epidemias; a contribuição de ações de saúde voltadas para as populações em áreas de contato antigo; e a organização dos povos indígenas em instituições que agem em sua 
própria defesa (Gomes, 1991; Melatti, 1999). Contudo, é provável que estes não tenham sido os únicos fatores responsáveis pelo crescimento verificado no final do século XX. Os altos níveis de natalidade encontrados nos últimos decênios, que entre alguns povos indígenas superaram os 50 nascimentos por mil habitantes (Pagliaro et al., 2002 e 2003), poderiam representar a recuperação de padrões reprodutivos ancestrais, existindo evidências de que nessas populações tais padrões são compatíveis com os seus anseios e necessidades estratégicas de poder e ocupação de território. Neste sentido, os povos indígenas tenderiam a ter domínio sobre o tamanho de família e de população que desejam, para atender às necessidades inerentes ao funcionamento de seus diferentes e complexos sistemas de organização sociocultural (Junqueira G Camargo, neste volume).

Tal constatação reforçaria a idéia de que os povos indígenas organizados podem ser soberanos quanto ao tamanho de suas populações. Muitos povos detêm práticas de restrição voluntária dos nascimentos, como ervas anticoncepcionais de efeito temporário ou definitivo, práticas abortivas naturais e mecânicas, além de prescrição do infanticídio em contingências específicas, o que lhes permitiria limitar a prole ao número desejado, como afirmam Camargo $G$ Junqueira, neste volume.

Os Kaiabi

Até meados do século XX, os Kaiabi, índios de filiação lingüística Tupi, ocupavam a região do Alto Teles Pires, desde a confluência do rio Verde até alguns quilômetros acima da barra do rio Peixoto de Azevedo, e parte da bacia do rio dos Peixes, afluente da margem direita do rio Arinos, no estado do Mato Grosso.

As primeiras notícias sobre os Kaiabi, muitas vezes confundidos com índios de outras etnias, datam do século XIX, quando expedições de mapeamento dos rios e etnográficas percorrem a região e encontram seus vestígios ou relatam referências feitas por seus inimigos tradicionais, como os Munduruku e os Bakairi (Grünberg, s/d; Travassos, 1984; Senra, 1999; Pagliaro, 2002).

Os contatos com a sociedade envolvente se intensificam no final do século XIX, quando a exploração da borracha na região do rio Tapajós se estende ao Mato Grosso, atinge as nascentes dos rios Arinos e do Paranatinga, envolvendo os índios Bakairi. Os Kaiabi do rio Verde e Alto Teles Pires começam a ser pressionados a abandonar suas terras pelos interessados na exploração dos seringais. Os conflitos, cada vez mais violentos, geram comentários de que os Kaiabi constituiriam um novo flagelo na região, como haviam sido os Bororo à época das explorações auríferas.

Os Kaiabi resistem por muito tempo e, a partir da década de 1940, por ocasião do terceiro boom da borracha e do enfraquecimento do Serviço de Proteção aos Índios (SPI), os seringais do Alto Teles Pires avançam rapidamente sobre o seu território, obrigando-os a mudar as aldeias para o médio curso deste rio. O saldo 
dessa convivência foi o deslocamento contínuo das aldeias, o fracionamento do grupo, o contágio por doenças e a depopulação.

Conforme Meliá (1993), em 1950 os Kaiabi estavam distribuídos geograficamente em três áreas: o grupo do Teles Pires, localizado entre a confluência do rio Verde e o rio Peixoto de Azevedo; o grupo da bacia do rio dos Peixes (Tatuy), afluente do Arinos; e o grupo do Sul do Pará, morador do Posto Indígena Caiabi, na região dos rios São Benedito e Cururuzinho, afluentes do Baixo Teles Pires.

A partir de 1952 uma família Kaiabi se desloca rumo ao Xingu. A decisão da mudança começou a ser cogitada a partir do encontro com os irmãos Villas Bôas, à frente da Expedição Roncador-Xingu, no rio Teles Pires, em 1949. A facilidade com que se adaptaram ao novo habitat do Xingu contribuiu para atrair outras famílias, ainda moradoras do antigo território e dos seringais, que paulatinamente foram se incorporando ao grupo inicial. Entre 1952 e 1966, registram-se migrações sucessivas de diversas famílias dos grupos do Teles Pires e do rio dos Peixes. O processo migratório² durou até 1973, quando chegam ao Parque algumas famílias que viviam no rio Cururuzinho (PA).

O Parque Indígena do Xingu (PIX) se estende da região dos formadores do rio Xingu, ao sul, e ao longo do curso deste rio até a Cachoeira de Von Martius, ao norte, nas proximidades da divisa com o Pará, compreendendo uma área de

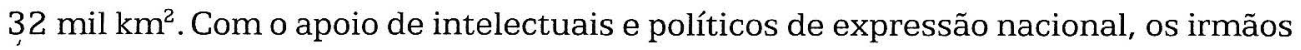
Villas Bôas participaram da luta que levou à criação do Parque, em 1961, para preservar os povos da região da especulação de terras que estava ocorrendo em Mato Grosso desde o declínio do terceiro ciclo da borracha.

Além dos Kaiabi, já citados, os Juruna alcançaram a região no início da década de 1920, os Txicão (Ikpeng) em 1967, os Beiço-de-Pau (Tapayuna) em 1970 e os Kren-Akrore (Panará) em 1975. Com estes movimentos migratórios, o Parque passou a contar com 17 tribos, pertencentes a quatro maiores troncos lingüísticos: Aruak (Meinako, Waurá, Yaualapiti), Karib (Kalapalo, Kuikuro, Matipu, Nafuká e Txikão), Gê (Kren-Akrore, Metuktire, Suyá e Tapayuna) e Tupi (Aweti, Kamaiurá, Juruna e Kaiabi) e os Trumai, de língua isolada.

A partir de 1965, a então Escola Paulista de Medicina (EPM), atual Universidade Federal de São Paulo (Unifesp), passou a desenvolver um programa de saúde no PIX, com o envio de equipes médicas periódicas que procediam à vacinação e atendiam às ocorrências clínicas. Este programa assegurou uma atenção privilegiada à saúde dos índios do Xingu em relação às populações de outras áreas indígenas (Baruzzi et al., 1978). Em 1999, com a criação de 34 Distritos Sanitários Especiais Indígenas (DSEI), pela Fundação Nacional de Saúde (Funasa), a Unifesp/ EPM assumiu a coordenação do DSEI Xingu, que hoje abriga uma população próxima de 4 mil índios. 
As informações geradas durante o longo período de atuação do programa de saúde da Unifesp/EPM no Xingu possibilitaram a avaliação do comportamento demográfico dos Kaiabi para o período 1970-99, apresentada a seguir.

\section{Fontes de dados e métodos de análise}

As fontes das informações utilizadas são os livros de registro e os prontuários médicos do arquivo da Unidade de Saúde e Meio Ambiente (Usma) da Unifesp/EPM, que contêm dados demográficos e de saúde dos povos que habitam o PIX, desde a implantação do programa de saúde. O arquivo, iniciado em 1966 e alimentado até o presente momento, constitui-se num sistema de informações contínuas, inédito no país, e que até 1999 incluiu 16 povos indígenas moradores do PIX, com a saída dos Panará em 1996.

A alimentação contínua deste sistema de informações assegurou o acompanhamento efetivo da população Kaiabi durante 30 anos, permitindo, além da análise transversal da mortalidade, natalidade e migrações, o acompanhamento de coortes de mulheres em idade reprodutiva, que se configura numa análise longitudinal retrospectiva da fecundidade.

\section{Comportamento demográfico dos Kaiabi do Xingu}

Os Kaiabi organizam-se em grupos locais formados por famílias extensas, definidas como famílias nucleares, geralmente ampliadas pelo casamento dos filhos. Por ocasião da visita do etnólogo George Grünberg (s/d) ao Xingu, em 1966, os 135 Kaiabi moradores da região estavam distribuídos em sete grupos locais, e alguns moravam com os Juruna. Em 1970, havia 204 Kaiabi no PIX, vivendo em oito grupos locais e nos Postos Indígenas Diauarum e Leonardo Villas Bôas. Em 1999, somavam 758 indivíduos, distribuídos em 12 grupos locais, nos Postos de Vigilância Tuiuiu e Rio Preto e no Posto Indígena Diauarum. Integrados aos Juruna, Suyá, Txikão, Trumai e Txucarramãe, havia, neste ano, 14 homens e 2 mulheres, que, com seus filhos, totalizavam 95 indivíduos. Estes últimos estão excluídos da presente análise, em razão de sua incorporação a outras culturas.

O crescimento médio anual da população no período 1970-99 foi de 4,5\% ao ảno. A migração foi irrelevante ao longo desses trinta anos, quando os movimentos de entradas e saídas do Parque e entre as aldeias Kaiabi e as de outros povos moradores do PIX foram constantes, mas insignificantes numericamente.

A Tabela 1 apresenta o movimento da população Kaiabi, segundo a ocorrência de eventos demográficos durante esse período. Os nascimentos (640) e os óbitos (98) registrados entre 1970 e 1999 resultaram num saldo vegetativo absoluto de 542 pessoas, responsável por $96,3 \%$ do crescimento absoluto da 
população (563). O número de imigrantes (40) superou o de emigrantes $(-19)$, tendo o saldo migratório positivo de 21 pessoas contribuído com apenas $3,7 \%$ do crescimento populacional.

Tabela 1 - Movimento da população Kaiabi do PIX, segundo eventos demográficos, 1970-1999

\begin{tabular}{|c|c|c|c|c|c|c|c|}
\hline \multicolumn{8}{|c|}{ Movimento da População Kaiabi do PIX, Segundo Eventos Demográficos, 1970-1999 } \\
\hline $\begin{array}{c}\text { Eventos } \\
\text { demográficos }\end{array}$ & $1970-74$ & $1975-79$ & $1980-84$ & $1985-89$ & 1990-94 & $1995-99$ & Total \\
\hline $\begin{array}{c}\text { População no } \\
\text { início do período }\end{array}$ & $195^{*}$ & 235 & 282 & 348 & 451 & 579 & - \\
\hline Nascimentos (+) & 43 & 68 & 82 & 109 & 141 & 197 & 640 \\
\hline Óbitos (-) & 14 & 19 & 15 & 20 & 18 & 12 & 98 \\
\hline Saldo Vegetativo & 29 & 49 & 67 & 89 & 123 & 185 & 542 \\
\hline Imigrantes $(+)$ & 13 & 0 & 0 & 15 & 9 & 3 & 40 \\
\hline Emigrantes (-) & -2 & -2 & -1 & -1 & -4 & -9 & -19 \\
\hline Saldo Migratório & 11 & -2 & -1 & 14 & 5 & -6 & 21 \\
\hline $\begin{array}{l}\text { Crescimento } \\
\text { Absoluto }\end{array}$ & 40 & 47 & 66 & 103 & 128 & 179 & 563 \\
\hline $\begin{array}{l}\text { População no final } \\
\text { do período }\end{array}$ & 235 & 282 & 348 & 451 & 579 & 758 & - \\
\hline
\end{tabular}

*excluídos os nascimentos de 1970.

Fonte de dados brutos: Usma - DMP/Unifesp/EPM.

Tabela 2 - População Kaiabi do PIX e taxas médias de crescimento anual (\%)

\begin{tabular}{|c|c|c|c|c|}
\hline \multicolumn{5}{|c|}{ População Kaiabi do PIX e taxas médias de crescimento anual (\%) } \\
\hline \multirow{2}{*}{ Anos } & \multirow{2}{*}{ População } & \multicolumn{3}{|c|}{ Taxas Médias de Crescimento (\%) } \\
\hline & & 5 anos & 10 anos & 30 anos \\
\hline 1970 & 204 & & & \\
\hline & & 2,87 & & \\
\hline 1974 & 235 & & 3,29 & \\
\hline & & 3,71 & & \\
\hline 1979 & 282 & & & \\
\hline & & 4,30 & & \\
\hline 1984 & 348 & & 4,81 & 4,47 \\
\hline & & 5,32 & & \\
\hline 1989 & 451 & & & \\
\hline & & 5,12 & & \\
\hline 1994 & 579 & & 5,33 & \\
\hline & & 5,54 & & \\
\hline 1999 & 758 & & & \\
\hline
\end{tabular}

Fonte de dados brutos: Usma - DMP/Unifesp/EPM. 
A Tabela 2 mostra a população Kaiabi entre 1970 e 1999 e as taxas de crescimento médio anual por períodos de cinco, dez e trinta anos. Estes dados apontam para um crescimento populacional progressivo, superando a média de $5 \%$ ao ano a partir de 1984 .

\section{Composição por idade e sexo}

As pirâmides etárias construídas para os anos de 1970 e 1999, em porcentagens, estão presentes nas Figuras 1 e 2 . A estrutura da população em 1970 reflete uma situação de excepcionalidade, retratando as gerações que sobreviveram aos contatos travados com as frentes de expansão e se deslocaram para o Xingu. O contorno destas pirâmides ilustra o processo de transição de um regime demográfico em que altos níveis de natalidade compensam a alta mortalidade, provocando o descenso ou crescimento estável da população, para um estágio em que a mortalidade declina e a natalidade aumenta mais e se mantém elevada, configurando uma etapa de elevado crescimento e de rejuvenescimento da população.

Figura 1 - Pirâmide etária dos Kaiabi do Xingu, 1970

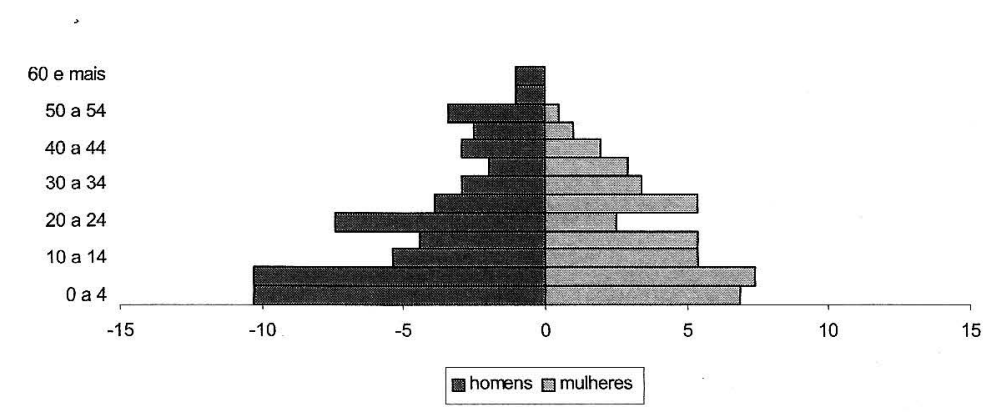

Figura 2 - Pirâmide etária dos Kaiabi do Xingu, 1999

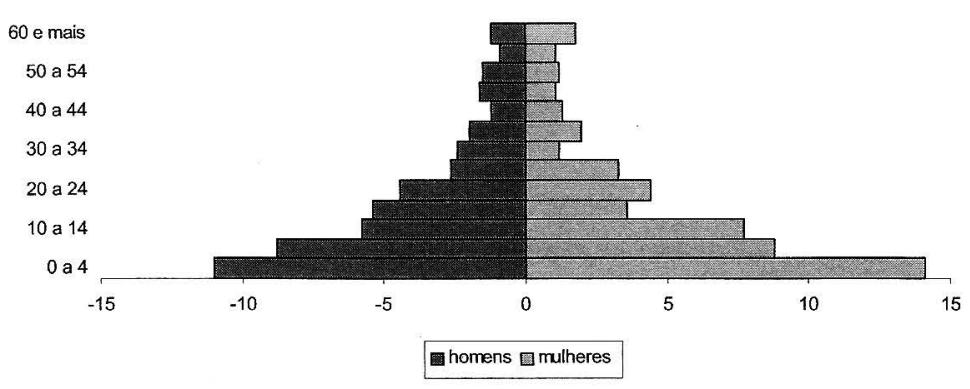


O resultado desse conjunto de fatores formou uma estrutura díspar com grandes lacunas em alguns grupos etários, embora não se deva perder de vista o fato de ser uma população pequena, na qual o impacto das pequenas mudanças absolutas pode acarretar importantes alterações relativas.

Os efeitos desse novo padrão demográfico refletem na distribuição proporcional da população por grandes grupos etários, que aponta para o aumento do peso relativo da população de 0 a 14 anos, de 45,6\% para 56,2\%, entre 1970 e 1999.

As médias de idade e as medianas estimadas para essa população, também confirmam o seu rejuvenescimento entre 1970-99. Neste período, a média de idade dos homens diminuiu de 2,6 anos, variando de 21,5 anos para 18,9 anos, e a das mulheres declinou em 1,8 ano, passando de 19,1 para 17,3 anos. Localizadas aos 17,5 anos para os homens e aos 15,5 anos para as mulheres, em 1970, as idades medianas diminuíram para 13 e 11 anos, respectivamente, em 1999, confirmando a tendência apontada pelas médias de idade no período.

Estudos demográficos sobre populações indígenas realizados nos últimos anos têm apontado para o rejuvenescimento das estruturas etárias de povos que, após um período de depopulação, retomaram altos níveis de fecundidade e estão em fase de recuperação populacional. Para tomar alguns exemplos, citam-se os Mucajai Yanomama (Early G Peters, 1990), Xavánte de Pimentel Barbosa e de Sangradouro-Volta Grande (Flowers, 1994; Souza G Santos, 2001; Coimbra Jr. et al., 2002), os Kren Akrore (Baruzzi et al., 1994), os Waurá (Pagliaro et al., 2001), os Tenetehara do Maranhão (Gomes, 2002), os Juruna (Pagliaro et al., 2003), os Kamaiurá (Pagliaro et al., 2004), e os Txikão (Maia et al., 2004).

A avaliação da composição por sexo dessa população oferece elementos importantes para a compreensão de seu processo de reprodução, sobretudo no que tange ao potencial de população disponível para garantir a reposição populacional, a formação de uniões conjugais e o desempenho de papéis e funções por gênero na sua organização social e de produção.

Tabela 3 - População Kaiabi do PIX segundo sexo, grandes grupos etários e razões de sexos, 1970-1999

\begin{tabular}{|c|c|c|c|c|c|c|c|c|c|c|c|c|}
\hline \multirow{2}{*}{$\begin{array}{l}\text { Grupos } \\
\text { Etários }\end{array}$} & \multicolumn{3}{|c|}{1970} & \multicolumn{3}{|c|}{1979} & \multicolumn{3}{|c|}{1989} & \multicolumn{3}{|c|}{1999} \\
\hline & $M$ & $\mathrm{~F}$ & $\mathrm{RS}$ & $\mathrm{M}$ & $\mathrm{F}$ & RS & $M$ & $\mathrm{~F}$ & $\mathrm{RS}$ & $M$ & $F$ & RS \\
\hline 0 a 14 & 53 & 40 & 132,5 & 76 & 60 & 126,7 & 122 & 117 & 104,3 & 194 & 232 & 83,6 \\
\hline 15 a 49 & 53 & 46 & 115,2 & 65 & 66 & 98,5 & 97 & 84 & 115,5 & 148 & 127 & 116,5 \\
\hline $50 e+$ & 11 & 1 & 1100,0 & 12 & 3 & 400,0 & 15 & 16 & 93,8 & 27 & 30 & 90,0 \\
\hline Total & 117 & 87 & 134,5 & 153 & 129 & 118,6 & 234 & 217 & 107,8 & 369 & 389 & 94,9 \\
\hline
\end{tabular}

Fonte de dados brutos: Usma - DMP/Unifesp/EPM. 
A razão de sexos dos Kaiabi, no ano de 1970, indicava haver, em média, 134,5 homens a cada cem mulheres, no conjunto da população (Tabela 3). A superioridade numérica da população masculina se confirma em todos os grupos etários e se mantém até o final da década de 1980, mesmo que em declínio progressivo. Em 1999, já havia mais mulheres do que homens no conjunto da população, sendo a razão de sexos 94,9 . Este comportamento estaria associado ao maior número de nascimentos do sexo feminino nos últimos decênios e não à redução da mortalidade feminina ou aumento da masculina, conforme apontado na análise dos diferenciais por sexo da mortalidade descrita em Pagliaro (2002). Nas idades entre 15 a 49 anos, quando o equilíbrio numérico de homens e mulheres na população pode influenciar os padrões das uniões conjugais e da procriação, a razão de sexos ainda é favorável aos homens $(116,5)$.

\section{Mortalidade}

Para conhecer o significado da morte entre os Tupi é nẹcessário, como afirma Laraia (1986:167), "conhecer a sua concepção do mundo sobrenatural". A morte significa para esses índios "a passagem da sociedade visível dos vivos à sociedade invisível dos ancestrais", e o ingresso nesta nova sociedade dependeria do esforço dos parentes vivos, que com alguns procedimentos estariam zelando pela passagem do morto para o plano dos espíritos (Hertz, 1970, citado em Laraia, 1986:168).

Quando morre um Kaiabi, seu corpo é pintado com urucum e amarrado com os braços cruzados sobre o peito, sendo deitado em sua rede e enterrado numa cova dentro de sua casa com seus adornos e objetos, conforme descrito em Grünberg (s/d). Ainda segundo este autor, se o morto for casado (a), a viúva (o) também se pinta com urucum, corta os cabelos e, por diversos dias chora e entoa canções, na companhia dos parentes para lamentar a morte. Os Kaiabi acreditam que parte da alma da pessoa que faleceu fica ligada aos parentes vivos, que se sentem física e mentalmente ligados a ela por longo período após a morte. Recolhendo-se às suas próprias casas, os familiares falam somente o necessário e em tom baixo. À noite, as mulheres choram e entoam canções no local em que o corpo foi enterrado (Oakdale, 1996).

As taxas de mortalidade geral observadas entre os Kaiabi oscilaram entre 9,3 e 14,6 óbitos por mil habitantes, de 1970 até 1989. A partir de 1990, os níveis de mortalidade geral definem uma tendência de declínio, diminuindo para 3,5 óbitos por mil habitantes entre 1995-1999. Para neutralizar o efeito das mudanças na estrutura da população, padronizaram-se estas taxas, usando-se como padrão a estrutura populacional do período 1995-99. As taxas padronizadas assumiram valores muito próximos aos das taxas observadas, confirmando a tendência de queda. 
O declínio dos níveis de mortalidade geral dos Kaiabi estaria relacionado à maior atuação do programa de saúde da Unifesp/EPM no Xingu nesta década, em decorrência da crise vivida pela Fundação Nacional do Índio (Funai), à intensificação da formação de agentes de saúde indígena e ao programa de imunização desenvolvido desde a implantação desse programa médico.

Para os Yanomama do rio Mucajai, Early G Peters (1990) observaram uma variação dos níveis de mortalidade geral de 36,3, para 26 por mil, no período 1955-1985. Para os autores, o declínio da mortalidade entre os Yanomama poderia ser explicado pela imunidade adquirida, esforços clínicos e preventivos do programa médico levado a efeito por missionários, intensificação das campanhas de vacinação e diminuição dos contatos com a sociedade nacional.

Apenas 21 óbitos de crianças Kaiabi menores de 12 meses foram registrados dentre os 640 nascimentos ocorridos durante os trinta anos de que trata esta investigação, resultando numa taxa média de mortalidade infantil (TMI) de 32,8 por mil nascimentos vivos entre 1970 e 1999 (Tabela 4). Entre 1975 e 1984, os níveis de mortalidade infantil foram elevados, tendo as taxas oscilado entre 73,5 a 85,4 óbitos por mil nascimentos vivos. A partir de 1985, a tendência de declínio começa a se esboçar, sendo nítida até o período de 1995-99, quando a TMI é de 15,2 óbitos a cada mil nascimentos vivos, nível que pode ser considerado baixo, se comparado ao de outras populações indígenas no Brasil.

No ano de 1999, a TMI do conjunto aa população do PIX foi de 29,6 por mil nascimentos vivos (Rodrigues, 1999), e a dos Waurá, também moradores do Parque, foi de 18,3 por mil (Pagliaro et al., 2001). Outras populações indígenas, como os Xavánte de Sangradouro-Volta Grande, apresentaram TMI de 87,1 por mil nascidos vivos no período 1993-1997, o que estaria associado a condições de saúde precárias (Souza G Santos, 2001).

Tabela 4 - Óbitos infantis, nascimentos e taxas de mortalidade infantil dos Kaiabi do PIX, 1970-1999

\begin{tabular}{cccc}
\hline Períodos & Óbitos Infantis & Nascimentos & TMI por mil \\
\hline $1970 / 74$ & 0 & 43 & - \\
$1975 / 79$ & 5 & 68 & 73,5 \\
$1980 / 84$ & 7 & 82 & 85,4 \\
$1985 / 89$ & 3 & 109 & 27,5 \\
$1990 / 94$ & 3 & 141 & 21,3 \\
$1995 / 98$ & 3 & 197 & 15,2 \\
\hline Total & 21 & 640 & 32,8 \\
\hline
\end{tabular}

Fonte de dados brutos: Usma - DMP/Unifesp/EPM. 
Na hipótese de que o registro de óbitos do programa de saúde da Unifesp ainda não estivesse satisfatoriamente implantado nos anos setenta e de que os óbitos infantis desta década estivessem subenumerados, seria provável que nos primeiros quinze anos do período estudado a mortalidade infantil fosse mais elevada do que o estimado e que o seu declínio tivesse sido ainda maior do que o observado.

Não se conhecem as TMI dos Kaiabi para o período de contato com as frentes expansionistas; porém, é válido supor que tenham sido muito altas. Os registros de óbitos e de nascimentos dos postos do Serviço de Proteção aos Índios (SPI) destinados aos Kaiabi são muito irregulares, não permitindo arriscar nenhuma estimativa para os quase trinta anos em que eles estiveram sob tutela do Serviço. Depoimentos de alguns Kaiabi do Xingu a respeito do período em que permaneceram nesses postos mencionam o grande número de mortes por epidemias de sarampo e de gripe, infecções respiratórias e tuberculose, enfatizando as mortes de crianças recém-nascidas.

Considerando-se o nível e a estrutura da mortalidade por idades, calculados por Pagliaro (2002), para os Kaiabi do Xingu, nos seis qüinqüênios do período 1970-1999, estimaram-se as esperanças de vida ao nascer desta população, por intermédio do Modelo Evadan (Campanário, neste volume).

Tabela 5 - Evolução da esperança de vida ao nascer dos Kaiabi do PIX, 1970-1999

\begin{tabular}{cc}
\hline Períodos & Esperança de vida (e0) \\
\hline $1970-1974$ & 48,5 \\
$1975-1979$ & 54,4 \\
$1980-1984$ & 55,1 \\
$1985-1989$ & 58,7 \\
$1990-1994$ & 63,3 \\
$1995-1999$ & 66,4 \\
\hline
\end{tabular}

Fonte de dados brutos: Usma - DMP/Unifesp/EPM.

Dos dados da Tabela 5 se depreende que o declínio dos níveis de mortalidade observado no período 1970-1999 propiciou um ganho estimado de, aproximadamente, 18 anos no tempo médio de vida dessa população, tendo a esperança de vida ao nascer aumentado de 48,5 anos (1970-1975) para 66,4 anos (1995-1999). 


\section{Natalidade}

Durante o período 1970 e 1999 nasceram 640 crianças vivas nas aldeias Kaiabi, sendo 312 do sexo masculino e 328 do feminino. Para o conjunto do período, a taxa bruta média de natalidade foi de 53,1 nascimentos a cada mil habitantes (Tabela 6).

Tabela 6 - Nascimentos, população e taxas brutas de natalidade (TBN) dos Kaiabi do PIX, 1970-1999

\begin{tabular}{cccc}
\hline Períodos & Nascimentos & $\begin{array}{c}\text { População } \\
\text { acumulada }\end{array}$ & TBN por mil \\
\hline $1970-1974$ & 43 & 1095 & 39,3 \\
$1975-1979$ & 68 & 1304 & 52,1 \\
$1980-1984$ & 82 & 1612 & 50,9 \\
$1985-1989$ & 109 & 2002 & 54,4 \\
$1990-1994$ & 141 & 2602 & 54,2 \\
$1995-1999$ & 197 & 3441 & 57,3 \\
\hline
\end{tabular}

Fonte de dados brutos: Usma - DMP/Unifesp/EPM.

As taxas de natalidade encontradas entre os Kaiabi do Xingu são similares às das populações indígenas que voltaram a crescer após longos contatos com nãoíndios. Entre os Xavánte de Pimentel Barbosa, Flowers (1994) encontrou uma taxa bruta média de natalidade de 51,4 nascimentos vivos por mil habitantes para o período 1977 - 1990. Entre os Xavánte de Sangradouro-Volta Grande, a TBN estimada por Santos G Souza (2001) foi de 57,7 por mil para o período 1993-1997.

Tabela 7 - Nascimentos por sexo e razões de sexo ao nascer dos Kaiabi do PIX, 1970-1999

\begin{tabular}{|c|c|c|c|}
\hline \multirow{2}{*}{ Períodos } & \multicolumn{2}{|c|}{ Sexo } & \multirow{2}{*}{ Razão de Sexo } \\
\hline & Masculino & Feminino & \\
\hline $1970 / 74$ & 21 & 22 & 0,9 \\
\hline $1975 / 79$ & 37 & 31 & 1,2 \\
\hline $1980 / 84$ & 45 & 37 & 1,2 \\
\hline $1985 / 89$ & 50 & 59 & 0,9 \\
\hline $1990 / 94$ & 71 & 70 & 1,0 \\
\hline 1995/99 & 88 & 109 & 0,8 \\
\hline Total & 312 & 328 & 0,9 \\
\hline
\end{tabular}

Fonte de dados brutos: Usma - DMP/Unifesp/EPM. 
As razões de sexo ao nascimento entre os Kaiabi são tão irregulares quanto as razões de muitas outras populações indígenas, podendo resultar do número excessivamente restrito da população (Tabela 7). Outro fator a ser considerado seria o infanticídio preferencial por sexo, como ocorre entre os Yanomama do rio Mucajai (Early G Peters, 1990). Os Tapirapé, quando estudados por Wagley, em 1951, possuíam famílias pequenas, de no máximo 3 filhos, sendo apenas 2 do mesmo sexo. Para manter este padrão o infanticídio é sancionado (Wagley, 1951). Para os Juruna, que durante algum tempo praticaram o infanticídio preferencial por sexo, Oliveira (1970) levanta a hipótese de que a regra de residência matrilocal - definida pela mudança do homem para a casa dos pais da esposa por ocasião do casamento - e, por conseqüência, o receio de perder homens, que saíam para casar com mulheres de outras tribos, pode ter suscitado a supervalorização do nascimento de meninas, quando estes índios manifestaram o desejo de crescer. Todavia, entre os Kaiabi do Xingu, que no passado sacrificavam gêmeos e bebês com deficiências físicas, assim como procediam os Tenetehara (Wagley, 1951) e os Nambiquara (Price, 1994), a prática de infanticídio preferencial por sexo não foi observada.

A Figura 3 mostra o comportamento das taxas de natalidade conjugado ao das taxas de mortalidade no período 1970-1999, proporcionando a visualização da importância da redução da mortalidade e do aumento da natalidade e sua manutenção em níveis altos para o processo de recuperação por que vem passando essa população.

Figura 3 - Taxas brutas de natalidade e de mortalidade dos Kaiabi do PIX, 1970-1999

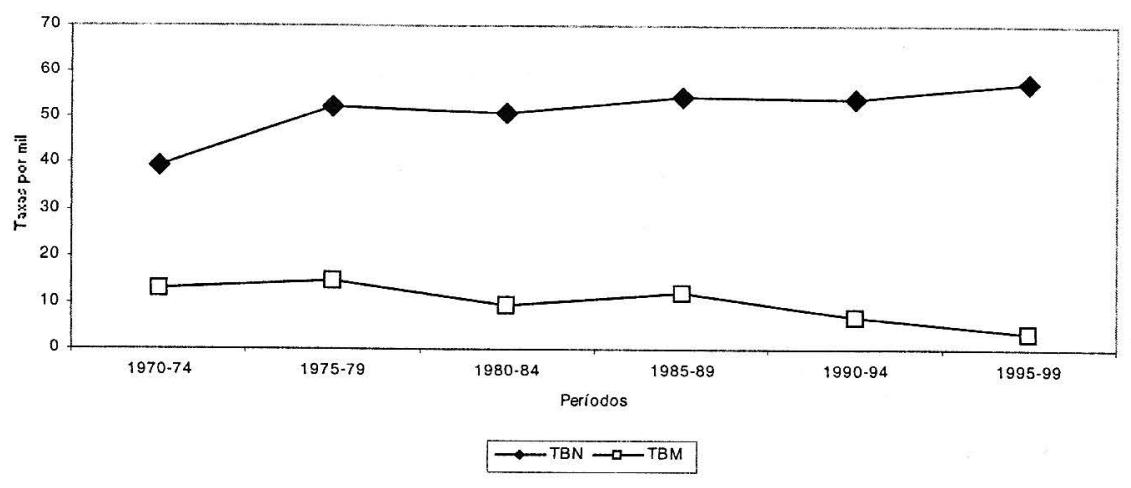

Padrões culturais, fecundidade e nupcialidade

Por volta dos doze ou treze anos de idade, os adolescentes Kaiabi passam, geralmente, por ritos de iniciação - a reclusão pubertária ou ayopot, em sua língua. 
Grünberg (s/d) observou entre os Kaiabi do rio dos Peixes que, durante este período, os rapazes permaneciam deitados em suas redes no interior de uma maloca, alimentando-se somente de chicha de milho preto (awatsi'un) e água, sendo proibidos de falar. Depois de um período, que variava de 3 a 7 dias, eram tatuados por seus pais e outros homens mais velhos numa cerimônia dirigida pelo pajé e só permitida para homens, na qual se cantava e tocava flauta. Na ocasião recebiam novos nomes. A prática do rito pubertário entre os rapazes sempre esteve ligada à tradição guerreira dos Kaiabi e, com o fim das guerras, parece ter entrado em decadência, sendo pouco freqüente no Xingu (Travassos, 1984)

Essa prática, no entanto, mantém-se para as meninas, ocorrendo após o aparecimento da primeira menstruação, quando as moças permanecem deitadas no interior da maloca, sem poder mexer em fogo, tecer algodão e conversar. Elas são banhadas pelas mães no interior da casa, obedecem a restrições alimentares e, ao final desse rito, ganham novos nomes (Travassos, 1984). Já sendo consideradas adultas, podem ter relações sexuais e assumir os compromissos do casamento, que, em geral, já estão combinados por sua família em obediência ao sistema de classificação de parentes.

Os casamentos são regidos por um sistema de parentesco conhecido na literatura antropológica como 'Iroquês' ou 'bifurca e mescla' (Junqueira, 1991; Grünberg, 1970). Este sistema distingue 'primos cruzados' e 'primos paralelos', aqueles considerados parentes 'classificatórios' e estes 'consangüíneos'. Em nível da geração de uma determinada pessoa, que é chamada de 'ego', 'primos cruzados' são os filhos das irmãs de seu pai e dos irmãos de sua mãe, que recebem o tratamento de tio e tia. 'Primos paralelos', por sua vez, são os filhos dos irmãos de seu pai e das irmãs de sua mãe, a quem 'ego' trata como a seus pais. Os parceiros conjugais preferidos são os primos cruzados ou os primos cruzados bilaterais, ou seja, os são filhos da irmã do pai e do irmão da mãe. Isto significa que o sistema mescla os irmãos do mesmo sexo dos pais de 'ego' e bifurca os irmãos de sexo diferente de seus pais (Junqueira, 1991; Gomes, 2002).

O 'levirato' ou o casamento entre tios e sobrinhas maternas era recomendado, ocorrendo, em geral, entre homens de grande prestígio, como destaca Grünberg (s/d). Entre as gerações mais velhas moradoras do PIX, verificaram-se alguns casamentos deste tipo. A 'poliginia sororal' ou o casamento de um homem com duas ou mais irmãs, também é prescrita, sendo observados diversos casamentos deste tipo entre os Kaiabi do Xingu, mesmo recentemente, mais freqüentes entre os homens de prestígio político ou religioso.

As relações sexuais entre os Kaiabi são em geral livres. Quando um rapaz tem intenção de se casar, dirige-se à mãe da parceira escolhida ou preferencial, que informa sua filha. Durante o período de 'namoro' deve presentear a sogra com caça, pesca e outros alimentos, além de objetos artesanais, como cestos e colares 
de tucum e inajá. O casamento não é precedido de nenhuma cerimônia, o rapaz se muda para a casa da esposa, onde ao novo casal é destinado um local para pendurar suas redes e seus utensílios e fazer seu fogo, configurando-se, assim, a regra de residência conhecida como matrilocal, que tem sua exceção entre os filhos de chefes de famílias extensas, que trazem as esposas para a casa do pai. O casal passa por um 'período de adaptação' antes que venham os filhos, podendo, na ocasião, mudar de nome (Grünberg, s/d).

A idade de início das uniões conjugais nas sociedades indígenas, assim como outrora se apresentava nas sociedades rurais, é, usualmente, muito jovem. Quando as regras sociais são cumpridas, as mulheres Kaiabi têm seus filhos, geralmente, aos 15 anos de idade. Mas há casos em que as mulheres iniciam a vida reprodutiva antes de completar esta idade. Como iniciam muito cedo a prática das relações sexuais e da procriação, o período reprodutivo dessas mulheres dura cerca de trinta anos, nascendo o último filho por volta dos 45 anos.

Segundo Oakdale (1996), entre os Kaiabi a concepção está relacionada ao calor e à energia do sol, sendo o pajé intermediário no encontro entre a mãe e o bebê, pois é ele quem introduz a alma da criança em sua mãe, através de seus sonhos. As crianças podem escolher entre quais casais querem nascer, e o pajé pode trabalhar para influenciar suas escolhas. A influência deste pode ser notada, também, na escolha do nome da criança; contudo, as novas gerações acreditam ser o pai que faz a alma da criança, sendo a mãe sua receptora.

A sociedade Kaiabi utiliza diferentes práticas contraceptivas, como ervas anticoncepcionais de efeito temporário ou definitivo, apesar de seu uso não ser livre e indiscriminado. Iefuká, auxiliar de enfermagem e cacique da aldeia Capivara, no Xingu, relatou que para evitar a gravidez os Kaiabi usam uma beberagem preparada com raízes de plantas, que é ingerida pela mulher durante vários dias, após as relações sexuais. Para suspender o seu efeito ingerem outra beberagem preparada com outros tipos de plantas, recuperando, desse modo, a capacidade de procriação. A anticoncepção definitiva é obtida por meio da ingestão de uma infusão de outras espécies de ervas. Para obter essas ervas, a interessada é levada pelo pajé, acompanhada por sua mãe, ao local onde nascem, o que institucionaliza o ato de anticoncepção (Iefuká Kaiabi, comunicação pessoal). Uma outra versão da anticoncepção definitiva é relatada por Oakdale (1996). Da mesma maneira como o sol nascente está relacionado à concepção, o poente liga-se à anticoncepção. Para não conceber mais, o pajé prepara um banho de folhas aromáticas que é espalhado sobre o corpo da mulher, estando esta voltada para o sol poente. O aroma das folhas penetra o seu corpo, mudando o seu sangue.

Durante a gravidez, como em algumas outras situações, os pais ainda hoje obedecem a restrições alimentares, nutrindo-se de vegetais e de algumas espécies de aves, peixes e animais silvestres. A relação sexual é proibida, mas, em 
geral, cessa somente nos últimos meses da gravidez e se reinicia tão logo o filho comece a andar. A mulher continua cuidando de seus afazeres, sendo poupada do transporte de cargas pesadas.

Segundo Grünberg (s/d), entre os Kaiabi do rio dos Peixes, o nascimento da criança se dava no mato ou em uma maloca com o auxílio de mulheres mais velhas. Ao nascer, a criança era lavada com água; o cordão umbilical era cortado com um pedaço de uma espécie de taquara, que diziam auxiliar no estancamento do sangue; o umbigo era atado com uma fibra de embira, sendo untado com a seiva de uma espécie vegetal em caso de sangramento. Depois de seco, o cordão umbilical era pendurado no pescoço da criança para protegê-la, sendo, mais tarde, enterrado. Os lóbulos da criança eram perfurados com um espinho de tucum e no orifício que resulta desta operação era passado um fio de algodão (Grünberg, s/d).

Ainda segundo este autor, o pai da criança se mantinha afastado ou deitado em sua rede, na qual recebia visitas e confeccionava um pequeno arco, se a criança fosse do sexo masculino, e um boneco ou um cesto, se fosse do sexo feminino, depositando os presentes na rede destinada ao bebê. O pai e seu irmão, ou a mãe e sua irmã, ou o chefe da família extensa e o pajé davam nome à criança. Ao passar da infância para a adolescência ela recebia outro nome, assim como ocorria em outras fases de sua vida (Grünberg, s/d).

Segundo dados levantados durante trabalho de campo realizado no Xingu, em 2000, algumas mães amamentam as crianças até que andem com desenvoltura, e, às vezes, por mais tempo. O desmame é gradual e durante este período a criança nunca é impedida de mamar, mas sim desestimulada. Aliás, como outros povos indígenas, os Kaiabi respeitam a vontade das crianças, educando-as com independência, liberdade e respeito, interferindo somente em situações de perigo.

Entre os Kaiabi do rio dos Peixes, o infanticídio era praticado em caso de nascimento de gêmeos, sendo a primeira criança a nascer preservada e as demais sacrificadas por serem consideradas filhas de outros pais. Os recém-nascidos com deficiências físicas eram igualmente sacrificados (Grünberg, s/d). Entre os Kaiabi do Xingu observaram-se gêmeos sobreviventes, sendo alguns já adultos (Pagliaro, 2002). Quanto a deficientes físicos, não são mais sacrificados, podendo o infanticídio ocorrer, ainda, em caso de adultério ou de violência sexual.

\section{Comportamento da fecundidade no tempo}

A análise transversal ou de momento da fecundidade contemplou três períodos de dez anos: 1970-79, 1980-89 e 1990-99. O critério adotado para definir as idades do período reprodutivo buscou contemplar as exceções à regra, definindo-se 12 anos para o início do período e 49 anos para o seu término. 
As taxas de fecundidade total (TFT) estimadas apontam para o aumento progressivo da fecundidade das mulheres Kaiabi, tendo a média de filhos nascidos vivos variado de 5,7 (1970-1979), para 8,4 (1980-1989) e para 9,5 filhos (19901999), como mostra a Tabela 8.

As taxas de fecundidade por idades $\left(f_{x}\right)$ das três décadas observadas refletem a tendência de aumento, apontando para as mudanças de níveis em cada grupo etário e as modificações do padrão etário da fecundidade nesses três períodos de tempo.

Tabela 8 - Taxas de fecundidade total (TFT) e específicas por idades das mulheres Kaiabi do PIX, por períodos decenais

\begin{tabular}{cccc}
\hline $\begin{array}{c}\text { Grupos de } \\
\text { Idades }\end{array}$ & $1970-79$ & $1980-89$ & $1990-99$ \\
\cline { 2 - 4 } & $\mathrm{fx}$ & $\mathrm{fx}$ & $\mathrm{fx}$ \\
\hline 12 a $14^{*}$ & 0,1622 & 0,0619 & 0,0674 \\
15 a 19 & 0,2768 & 0,2761 & 0,3309 \\
20 a 24 & 0,2828 & 0,3248 & 0,3691 \\
25 a 29 & 0,2414 & 0,3761 & 0,3728 \\
30 a 34 & 0,0957 & 0,2921 & 0,3306 \\
35 a 39 & 0,1304 & 0,2533 & 0,2650 \\
40 a 44 & 0,0169 & 0,1059 & 0,1341 \\
45 a 49 & 0,0000 & 0,0417 & 0,0541 \\
\hline TFT* & 5,7 & 8,4 & 9,5 \\
\hline
\end{tabular}

* as estimativas consideraram o intervalo de 3 anos do grupo 12-14 anos. Fonte de dados brutos: Usma - DMP/Unifesp/EPM.

Tabela 9 - Distribuição das taxas de fecundidade por idades das mulheres Kaiabi do PIX, 1970-1999 (\%)

\begin{tabular}{cccccccccc}
\hline \multirow{2}{*}{ Períodos } & Total & 12 a 14 & 15 a 19 & 20 a 24 & 25 a 29 & 30 a 34 & 35 a 39 & 40 a 44 & 45 a 49 \\
\hline $1970-1979$ & 100,0 & 13,5 & 23,0 & 23,5 & 20,0 & 7,9 & 10,8 & 1,3 \\
$1980-1989$ & 100,0 & 3,6 & 15,9 & 18,8 & 21,7 & 16,9 & 14,6 & 6,1 & 2,4 \\
$1990-1999$ & 100,0 & 3,5 & 17,2 & 19,2 & 19,4 & 17,2 & 13,7 & 7,0 & 2,8 \\
\hline
\end{tabular}

Fonte de dados brutos: Usma - DMP/Unifesp/EPM.

O comportamento irregular dessas taxas na década de 1970 pode ser atribuído à variação dos pequenos números e a possíveis erros na estimativa das idades das mulheres nascidas antes da implantação do registro do programa de 
saúde. Nesta década, a fecundidade foi mais relevante no grupo etário de 20 a 24 anos; o nível de fecundidade das mulheres muito jovens (12 a 14 anos) foi mais elevado do que o das décadas posteriores, e o das mulheres maiores de 20 anos foi mais baixo. Para as décadas de 1980 e 1990, observaram-se mudanças no padrão de fecundidade, sendo as mulheres com idades entre 25 e 29 anos as que têm o mais elevado nível de fecundidade. A fecundidade mais concentrada nas idades jovens, observada na década de 1970, dá lugar a uma maior participação das mulheres mais velhas. Na década de 1970, as mulheres com idades até 29 anos já haviam contribuído com $80 \%$ da fecundidade total. Nas décadas de 1980 e de 1990 , as mulheres destas idades contribuíram com $60 \%$ e 59,3\%, respectivamente, verificando-se um prolongamento do período reprodutivo (Tabela 9).

\section{Comportamento da fecundidade através das gerações}

Com as informações sobre data de nascimento das mulheres e de seus filhos foi possivel acompanhar, desde o início do período reprodutivo, uma coorte de mulheres com fecundidade completa e cinco coortes de mulheres que ainda não tinham completado o período reprodutivo. A Tabela 10 resume algumas características dessas coortes.

Tabela 10 - Descrição da vida reprodutiva das mulheres Kaiabi por coortes de nascimento

\begin{tabular}{|c|c|c|c|c|c|c|}
\hline Variáveis investigadas & Coorte 1 & Coorte 2 & Coorte 3 & Coorte 4 & Coorte 5 & Coorte 6 \\
\hline $\begin{array}{l}\text { Ano de nascimento } \\
\text { das mulheres }\end{array}$ & $1950-1954$ & 1955-1959 & $1960-1964$ & $1965-1969$ & $1970-1974$ & $1975-1979$ \\
\hline Número de mulheres & 12 & 9 & 16 & 11 & 23 & 31 \\
\hline $\begin{array}{l}\text { Número de mulheres } \\
\text { que tiveram filhos }\end{array}$ & 12 & 9 & 16 & 11 & 23 & 31 \\
\hline $\begin{array}{l}\text { Ano de nascimento } \\
\text { do } 1^{\circ} \text { filho vivo }\end{array}$ & 1964 & 1970 & 1972 & 1980 & 1982 & 1989 \\
\hline $\begin{array}{l}\text { Ano de nascimento } \\
\text { do último filho }\end{array}$ & 1998 & 1998 & 1999 & 1999 & 1999 & 1999 \\
\hline $\begin{array}{l}\text { Número de filhos } \\
\text { nascidos vivos }\end{array}$ & 84 & 78 & 137 & 58 & 105 & 92 \\
\hline $\begin{array}{l}\text { Idade da mãe ao nascimento } \\
\text { do último filho vivọ (anos) }\end{array}$ & 44 & 44 & 39 & 34 & 29 & 24 \\
\hline $\begin{array}{l}\text { Média de filhos tidos nascidos } \\
\text { vivos até idade } \mathrm{x}\end{array}$ & 7,0 & 8,7 & 8,6 & 5,7 & 4,5 & 3,0 \\
\hline $\begin{array}{l}\text { Média de idade ao } \\
\text { nascimento do } 1^{\circ} \text { filho } \\
\text { vivo (anos) }\end{array}$ & 18,7 & 16,8 & 15,4 & 17,5 & 17,0 & 16,0 \\
\hline $\begin{array}{l}\text { Intervalo médio entre os } \\
\text { nascimentos (anos) }\end{array}$ & 2,9 & 2.8 & 2,6 & 3,1 & 2,4 & 2.5 \\
\hline
\end{tabular}

Fonte de dados brutos: Usma - DMP/Unifesp/EPM. 
A média de idade ao nascimento do primeiro filho das diferentes coortes flutuou muito, apresentando tendência de declínio progressivo a partir da coorte 4 (17,5 anos) com mulheres nascidas entre 1965-69, atingindo 16 anos na coorte 6 (a mais jovem) e apontando para o rejuvenescimento do padrão etário da fecundidade das mulheres das gerações mais jovens. Os intervalos entre os nascimentos variam entre 2,4 e 3,1 anos.

As estimativas da descendência final da coorte 1 e da coorte 2 , se considerarmos que as mulheres desta última coorte, também, já encerraram o período reprodutivo, indicam elevados níveis de fecundidade até os 40-44 anos: 7,0 e 8,7, em média, respectivamente (Tabela 11).

Tabela 11 - Parturições médias e acumuladas das coortes de mulheres Kaiabi do PIX, por grupos de idades

\begin{tabular}{|c|c|c|c|c|c|c|c|c|c|c|c|c|}
\hline \multirow{2}{*}{$\begin{array}{l}\text { Grupos de } \\
\text { Idades }\end{array}$} & \multicolumn{2}{|c|}{ Coorte 1} & \multicolumn{2}{|c|}{ Coorte 2} & \multicolumn{2}{|c|}{ Coorte 3} & \multicolumn{2}{|c|}{ Coorte 4} & \multicolumn{2}{|c|}{ Coorte 5} & \multicolumn{2}{|c|}{ Coorte 6} \\
\hline & $F x$ & $\begin{array}{c}\text { Fx } \\
\text { acumulada }\end{array}$ & $F x$ & $\begin{array}{c}\mathrm{Fx} \\
\text { acumulada }\end{array}$ & Fx & $\begin{array}{c}F x \\
\text { acumulada }\end{array}$ & $F x$ & $\begin{array}{c}F x \\
\text { acumulada }\end{array}$ & Fx & $\begin{array}{c}\mathrm{Fx} \\
\text { acumulada }\end{array}$ & $F x$ & $\begin{array}{c}\mathrm{Fx} \\
\text { acumulada }\end{array}$ \\
\hline 12 a 14 & 0.167 & 0,167 & 0,222 & 0,222 & 0,438 & 0,438 & 0,091 & 0.091 & 0,217 & 0,217 & 0,129 & 0,129 \\
\hline 15 a 19 & 0,833 & 1,000 & 1,444 & 1,666 & 1,625 & 2,063 & 1,182 & 1,273 & 1,391 & 1,608 & 1,677 & 1,806 \\
\hline 20 a 24 & 1,583 & 2,583 & 1,889 & 3,555 & 1,938 & 4,001 & 1,364 & 2,637 & 1,87 & 3,478 & 1,161 & 2,967 \\
\hline 25 a 29 & 1,750 & 4,333 & 1,889 & 5,444 & 2,063 & 6,064 & 1,546 & 4,183 & 1,044 & 4,522 & & \\
\hline 30 a 34 & 1,167 & 5,500 & 1,333 & 6,777 & 1,563 & 7,627 & 1,091 & 5,274 & & & & \\
\hline 35 a 39 & 1,083 & 6,583 & 1,222 & 7,999 & 0,938 & 8,565 & & & & & & \\
\hline 40 a 44 & 0,417 & 7,000 & 0,667 & 8,666 & & & & & & & & \\
\hline 45 a 49 & 0,000 & & & & & & & & & & & \\
\hline Total & 7.000 & & 8,666 & & & & & & & & & \\
\hline
\end{tabular}

Fonte de dados brutos: Usma - DMP/Unifesp/EPM.

As parturições médias das gerações de mulheres que ainda não completaram o período reprodutivo, integrantes das coortes 3, 4, 5 e 6, indicam uma tendência de elevação da fecundidade para níveis ainda mais altos. Na coorte 3 , por exemplo, até o grupo etário 30-39 anos, a parturição média acumulada era de 8,6 filhos nascidos vivos, sendo, portanto, mais elevada do que a das coortes 1 e 2 neste mesmo grupo etário.

Assim como observado na análise da fecundidade por períodos de tempo (transversal), a avaliação das parturições médias das coortes de mulheres, até a 
idade em que puderam ser acompanhadas (longitudinal), também aponta para o aumento da fecundidade. No entanto, diferentemente do indicado no primeiro modelo de análise desenvolvido, a observação por coortes captou mudanças no calendário da fecundidade, ocorridas no sentido de rejuvenescimento de seu padrão etário, especialmente, entre as coortes que puderam ser acompanhadas por um período de tempo mais prolongado (1, 2 e 3 ) e nas primeiras idades do período reprodutivo, ao passo que a análise transversal apontou para modificações no sentido do envelhecimento.

A melhoria das condições de saúde e de sobrevivência da população proporcionada pela garantia de posse de suas terras são fatores que influenciaram a elevação da fecundidade entre os Kaiabi, que atingiu nível semelhante ao da fecundidade natural das mulheres Hutterites da América do Norte (Leridon, 1977). Os maiores aumentos se deram entre as mulheres de 15 a 24 anos, revelando uma tendência de rejuvenescimento do padrão reprodutivo. Entretanto, o impacto da melhoria das condições de saúde verificou-se, também, entre as mulheres com mais de 30 anos que, igualmente, tiveram seus níveis de fecundidade aumentados. Neste sentido, a atenção à saúde da mulher, sobretudo no período pré-natal, contribuiu para aumentar as possibilidades destas mulheres levarem as gravidezes a termo.

Outros efeitos indiretos da queda da mortalidade sobre o aumento da fecundidade podem ser mencionados, como a maior estabilidade das uniões conjugais antes interrompidas com freqüência, em razão da morte de um dos cônjuges. A aquisição do equilíbrio entre os sexos propiciou aos que se separaram ou enviuvaram maior facilidade para encontrar novos parceiros conjugais e dar continuidade à sua vida reprodutiva. O crescimento populacional em seu conjunto proporcionou um maior número de opções de casamentos prescritos pelo sistema de classificação de parentes dos Kaiabi, favorecendo as uniões antes dificultadas pela escassa oferta de parceiros.

O elevado nível de fecundidade observado entre os Kaiabi estaria associado a padrões reprodutivos caracterizados por curtos intervalos de tempo entre os nascimentos e pelo início precoce da procriação. Esta relação foi encontrada em outras sociedades indígenas como os Yanomama do rio Mucajai (Early G Peters, 1990), os Xavánte de Pimentel Barbosa (Flowers, 1994; Coimbra Jr. et al., 2002) e de Sangradouro-Volta Grande (Souza G Santos, 2001).

\section{Nupcialidade}

Com a perda populacional ocorrida durante o período de contato com as frentes de expansão, os Kaiabi ficaram com poucas opções de uniões conjugais prescritas, sendo obrigados a aceitar tipos de uniões recomendadas, mas pouco 
usuais, como as de tios e sobrinhas (levirato), ou ainda, para não descumprir as regras do sistema de parentesco, a procurar cônjuges entre os povos vizinhos. Isso ocorreu nos primeiros anos após a chegada da tribo ao PIX, quando foram registrados diversos casamentos de Kaiabi com os Juruna, Suyá, Trumai e Txikão. Tais uniões exogâmicas foram absorvidas pelo grupo, para que a reposição populacional não fosse ameaçada, mostrando como um problema demográfico pode modificar temporariamente arranjos familiares e culturais. As regras de casamento voltaram a ser operacionalizadas pelos Kaiabi, que, após um período de crescimento populacional, agora possuem diversas opções de união dentro das categorias prescritas, embora, atualmente, nem todos os casamentos obedeçam às regras tradicionais.

As informações sobre o estado conjugal analisadas a seguir referem-se ao ano de 1999 e apenas à população de 15 ou mais anos moradora das aldeias Kaiabi do PIX. As categorias de análise consideradas são: solteiros, casados por tipos de união, separados e viúvos que permaneceram sós. A Tabela 12 resume estas informações.

Entre os Kaiabi, como em outras sociedades indígenas, o celibato deliberado é raro. Em 1999, ainda permaneciam solteiros 45 homens e 20 mulheres Kaiabi, sendo a maioria com idades inferiores a 20 anos. Quanto à viuvez, quando ocorre, geralmente a viúva ou viúvo se casam novamente. Neste ano, havia 1 homem e 6 mulheres viúvas, todos com mais de 50 anos, e nenhuma pessoa separada.

Entre as 128 uniões conjugais identificadas por intermédio das genealogias, 118 (92,2\%) eram monogâmicas e 10 (7,8\%) poligínicas. Todos estes casamentos poligínicos envolviam um homem casado com duas irmãs, configurando-se como poliginia sororal. Cabe destacar que, entre as 138 mulheres casadas, 8 tinham menos de 15 anos; uma delas vivia em união poligínica.

Tabela 12 - Estado conjugal dos Kaiabi do PIX de 15 ou mais anos de idade, por sexo, 1999

\begin{tabular}{lccc}
\hline Estado Conjugal & Masculino & Feminino & Total \\
\hline Solteiros & 45 & 20 & 65 \\
Casados & 128 & 138 & 266 \\
Uniões monogâmicas & 118 & 118 & 236 \\
Uniões poligínicas & 10 & 20 & 30 \\
Viúvos & 1 & 5 & 6 \\
\hline Total & 174 & 163 & 337 \\
\hline
\end{tabular}

Fonte de dados brutos: Usma - DMP/Unifesp/EPM. 
Dentre as dez uniões caracterizadas como poligínicas, três se constituíram no início da década de 1970, duas na segunda metade da década de 1980 e cinco durante a década de 1990. Apesar de representarem somente $7,8 \%$ do total das uniões e envolverem $14,5 \%$ das mulheres casadas, a persistência desse tipo de união conjugal estaria indicando que os Kaiabi têm preferido manter seus padrões tradicionais de casamento, evitando as uniões exogâmicas.

\section{Considerações finais}

A história recente dos Kaiabi relata que a expansão da exploração seringalista para a região que ocupavam ao norte do Mato Grosso, a partir do final do século XIX, provocou o deslocamento de suas aldeias e a integração aos seringais, culminando com a mudança de uma parte do grupo para o Xingu, a partir de 1952 . A mudança fracionou mais o grupo, acarretando a perda de acesso a recursos vegetais e animais que não são encontrados na região do Xingu. No entanto, a saga dos Kaiabi não impediu que sobrevivessem, por mais que tenham perdido, na mudança, práticas culturais e força política, depois recuperadas com o crescimento populacional e a posição de destaque que ocupam, hoje, na região do Diauarum, no PIX.

Em franco processo de recuperação populacional, os Kaiabi do PIX tiveram sua população aumentada de 204 para 758 indivíduos entre 1970 e 1999, correspondendo a um crescimento médio da ordem de 4,5\% ao ano. Contribuíram para este elevado crescimento populacional o desejo e a decisão de crescer, associados a diversas circunstâncias favoráveis, como a cessação de conflitos com as frentes expansionistas da sociedade nacional, a menor exposição às epidemias e a garantia do território. A assistência médica foi fundamental para a melhoria das condições de saúde, com a adoção de medidas curativas e preventivas.

Para tanto, a conjugação de fatores favoráveis ao cumprimento da fase de recuperação populacional dos Kaiabi com sucesso está colocada: o elevado número de homens e mulheres em idade reprodutiva, resultado do efeito inercial da alta natalidade e da mortalidade decrescente, favorecerá, ainda por um período de tempo, a manutenção do ritmo de crescimento da população; condições de saúde favoráveis; garantia do território e da manutenção de sua subsistência. $\mathrm{O}$ desafio no presente - a preservação da identidade cultural - está nas mãos dos jovens e das lideranças.

Agradecimentos

A autora agradece aos Kaiabi pela colaboração prestada durante os quatro anos em que esteve envolvida com esta investigação. 
1 Extraído da tese de doutorado homônima, defendida na Faculdade de Saúde Pública da Universidade de São Paulo, em 2002, cujo título faz referência à denominação de Adolphe Landry (Landry, 1984) para o processo de transição demográfica.

2 Uma descrição mais detalhada do processo migratório dos Kaiabi para o Xingu pode ser encontrada em Pagliaro (2005).

Referências Bibliográficas

BARUZZI, R. G.; MARCOPITO, L. F. G IUNES, M. Programa Médico Preventivo da Escola Paulista de Medicina no Parque Nacional do Xingu. Revista de Antropologia, 21:155170, 1978.

BARUZZI, R. G. et al. Os índios Panará: a busca pela sobrevivência. Anais do Encontro Nacional de Estudos Populacionais, 2:225-243, 1994.

COIMBRA Jr. et al. The Xavante in Transition: health, ecology, and bioanthropology in Central Brazil. Michigan: University of Michigan Press, 2002.

EARLY, J. D. G PETERS, J. F. The Population Dynamics of the Macujai Yanomama. New York: Academic Press, 1990.

FLOWERS, N. M. Crise e recuperação demográfica: os Xavánte de Pimentel Barbosa, Mato Grosso. In: SANTOS, R. V. G COIMBRA Jr., C. E. A. (Orgs.) Saúde dos Povos Indígenas. Rio de Janeiro: Ed. Fiocruz, 1994. p.213-242.

GOMES, M. P. Os Índios e o Brasil: ensaio sobre um holocausto e sobre uma nova possibilidade de convivência. 2.ed. Petrópolis: Vozes, 1991.

GOMES, M. P. O Índio na História: o povo Tenetehara em busca da liberdade. Petrópolis: Vozes, 2002.

GREENE, M. E. G CROCKER, W. H. Some demographic aspects of the Canela indians of Brazil. South American Indian Studies, 4:47-62, 1994.

GRÜNBERG, F. Tentativas de análisis del sistema de parentesco de los Kayabí (Brasil Central). Separata del Suplemento Antropológico, 5:277-287, 1970.

GRüNBERG, G. Contribuições para a Etnografia dos Kayabi do Brasil Central, s/d. Tese de Doutorado, Viena: Faculdade de Filosofia, Universidade de Viena (tradução de E. G. Wenzel G J. E. Dornstauder). São Paulo: Centro Ecumênico de Documentação e Informação.

ISA (INSTITUTO SOcioAmbIEnTAL). Povos Indígenas do Brasil. São Paulo: ISA, 2001.

JUNQUEIRA, C. Antropologia Indígena: uma introdução. São Paulo: Educ, 1991. (Série Trilhas) 
LANDRY, A. La Révolution Démographique. Etudes et Essais sur les Problèmes de la Population. Paris: Ined. (reedição da publicação de 1934), 1982.

LARAIA, R. B. Tupi: índios do Brasil atual. São Paulo: Ed. da Universidade de São Paulo, 1986.

LERIDON, H. Human Fertility: the basic components. Chicago: Chicago University Press, 1977.

MAIA, S. F. et al. Recuperação populacional dos Txicão (Ikpeng), Parque Indígena do Xingu, Mato Grosso, Brasil. In: XIV ENCONTRO NACIONAL DE ESTUDOS POPULACIONAIS (CD-ROM). Caxambu: Associação Brasileira de Estudos Populacionais - Abep, 2004.

MELATTI, J. C. Índios do Brasil. 7.ed. São Paulo/Brasília: Hucitec/Ed. da UnB, 1993.

MELATTI, J. C. Crescimento populacional. Brasil Indígena (Fundação Nacional do Índio), Ano 1, 1:24-25, 1999.

MELIÁ, B. Os Caiabi não-xinguanos. In: COELHO, V. P. (Org.) Karl von den Steinen: um século de antropologia no Xingu. São Paulo: Edusp, 1993. p.485-509.

OAKDALE, S. The Power of Experience: agency and identity in kayabi healing and political process in the Xingu Indigenous Park, 1996. Tese de Doutorado, Chicago: Chicago University.

OLIVEIRA, A. E. Os Índios Juruna do Alto Xingu. Dédalo, ano VI, jun/dez. 11-12:1-285, 1970.

PAGLIARO, H. A Revolução Demográfica dos Povos Indígenas: a experiência dos Kaiabi do Parque Indígena do Xingu, Mato Grosso (1970-1999), 2002. Tese de Doutorado, São Paulo: Faculdade de Saúde Pública, Universidade de São Paulo.

PAgliaro, H. A mudança dos Kaiabi para o Parque Indígena do Xingu: uma história de sucesso demográfico. In: BARUZZI, R. G. G JUNQUEIRA, C. (Orgs.) História, Saúde e Cultura. Parque Indígena do Xingu. (no prelo), 2005.

PAGLIARO, H. et al. Health Indicators and demographic behaviors of the Waurá (Aruak Indians) from 1970 to 1999. Central Brazil. In: Proceedings of the XXIV $V^{\text {th }}$ Iussp General Population Conference, p.42, Salvador, 2001.

PAGLIARO, H. et al. Índios Juruna (Yudjá): Comportamento demográfico e condições de saúde. Parque Indígena do Xingu (1970-1999). In: VII CONGRESSO BRASILEIRO DE SAÚDE COLETIVA, Resumos, p.620. Brasília: Associação Brasileira de Saúde Coletiva - Abrasco, 2003.

PAGLIARO, H. et al. Comportamento demográfico dos Índios Kamaiurá, Parque Indígena do Xingu, Mato Grosso, Brasil. In: XIV ENCONTRO NACIONAL DE ESTUDOS POPULACIONAIS (CD-ROM). Caxambu: Associação Brasileira de Estudos Populacionais - Abep, 2004.

PICCHI, D. Observations about a Central Brazilian indigenous population: the Bakairi. South American Indian Studies, 4:37-46, 1994.

PRICE, D. Notes on Nambiquara demography. South American Indian Studies, 4:63-76, 1994. 
RIBEIRO, D. Prefácio. In: GOMES, M. P. Índios do Brasil: ensaio sobre um holocausto e uma nova possibilidade de convivência. 2.ed. Petrópolis: Vozes, 1991. p.9-13.

RODRIGUES, D. Relatório de Atividades. Distrito Sanitário Especial Indígena do Xingu. São Paulo: Departamento de Medicina Preventiva/ Unidade de Saúde e Meio Ambiente/ Universidade Federal Paulista - Escola Paulista de Medicina, 1999.

SENRA, K. Kaiabi. Disponível em http://www.socioambiental. org/website/epi/kaiabi. Htm. Consulta em 6 de julho de 2000, 1999.

SOUZA, L. G. G SANTOS, R. V. Perfil demográfico da população indígena Xavánte de Sangradouro - Volta Grande, Mato Grosso (1993-1997), Brasil. Cadernos de Saúde Pública, 17:355-366, 2001.

TRAVASSOS, E. Xamanismo e Música entre os Kayabi, 1984 Dissertação de Mestrado, Rio de Janeiro: Faculdade de Filosofia, Universidade Federal do Rio de Janeiro.

WAGLEY, C. Cultural influences on population: a comparison of two Tupi tribes. Revista do Museu Paulista, 5:95-104, 1951. 